\title{
Artigo
}

Dossiê: Tempo de pausa ou de crise?

\section{A educação infantil, o SAEB e o contexto gerado pela Covid-19}

La educación infantil, el SAEB y el contexto generado por la Covid-19

Early childhood education, the SAEB and the context generated by Covid19

\author{
Virgínia Louzada
}

Universidade do Estado do Rio de Janeiro, Brasil

Recebido em: 07/09/2020

Aceito em: 03/11/2020

\section{Resumo}

Este artigo pretende discutir a inclusão da Educação Infantil no SAEB e o possível cenário gerado pela Covid-19. Sistematiza dados produzidos através de revisão bibliográfica. Discute essa inclusão a partir de documentos sobre o SAEB, sobre a Covid-19 e as pesquisas da área de avaliação. Chega à conclusão de que há um contexto anterior que pretende antecipar o processo de alfabetização para essa etapa. Leva em conta que tal necessidade pode parecer mais urgente no horizonte pós-pandemia, uma vez que 0 desafio de dar conta da questão da alfabetização pode aumentar consideravelmente, por conta da interrupção das atividades escolares presenciais.

Palavras-chave: Educação infantil. Políticas de avaliação. Avaliação externa. Alfabetização. Covid-19.

\section{Resumen}

Este artículo tiene como objetivo discutir la inclusión de la Educación Infantil en SAEB y el posible escenario generado por Covid-19. Sistematiza los datos producidos a través de la revisión bibliográfica. Se discute esta inclusión basándose en documentos sobre SAEB, Covid-19 e investigaciones en el área de evaluación. Se llega a la conclusión de que existe un contexto previo que pretende anticipar el proceso de alfabetización para la etapa. Toma en cuenta que esta necesidad puede parecer más urgente en el horizonte pos pandémico, ya que el desafío de abordar el tema de la alfabetización puede 
incrementarse considerablemente, debido a la interrupción de las actividades de la escuela.

Palabras clave: Educación infantil. Políticas de evaluación. Evaluación externa. Alfabetización. Covid-19.

\begin{abstract}
This article aims to discuss the inclusion of Early Childhood Education in SAEB and the possible scenario generated by Covid-19. It systematizes data produced through bibliographic review. It discusses this inclusion based on documents about SAEB, Covid-19 and research in the area of evaluation. It comes to the conclusion that there is a previous context that intends to anticipate the literacy process for the stage. It takes into account that this need may seem more urgent in the post-pandemic horizon, since the challenge of addressing the issue of literacy can increase considerably, due to the interruption of classroom activities.
\end{abstract}

Keywords: Early childhood education. Evaluation policies. External evaluation. Literacy. Covid-19.

\title{
Considerações iniciais
}

Este artigo objetiva discutir o cenário de inclusão da educação infantil (El) no Sistema de Avaliação da Educação Básica (SAEB) e possíveis desdobramentos desta inserção no atendimento à faixa etária no cenário educacional gerado pela Covid-19. A El foi incorporada ao SAEB em 2019 (Brasil, 2019), que passou a ter, como população alvo do sistema, amostra de turmas de creche e de pré-escola de instituições públicas e conveniadas com o setor público, em caráter de estudo piloto.

O SAEB é o principal sistema de avaliação da educação básica. Foi estabelecido pela Portaria no 1.795 (Brasil, 1994) e modificado pela Portaria no 931 (Brasil, 2005). Segundo o Instituto Nacional de Estudos e Pesquisas Educacionais Anísio Teixeira (Inep), tem por objetivo avaliar a educação básica brasileira e (re)formular/monitorar as políticas públicas voltadas para esta etapa, contribuindo para a melhoria de sua qualidade. Até 2019, era composto por três avaliações externas e em larga escala, a saber:

a) Avaliação Nacional da Educação Básica (ANEB): avaliava, a cada dois anos, uma amostra dos/as alunos/as regularmente matriculados/as no $5^{\circ}$ e $9^{\circ}$ ano do ensino fundamental e no $3^{\circ}$ ano do ensino médio, das escolas públicas e privadas localizadas em áreas urbanas e rurais do país;

b) Avaliação Nacional do Rendimento Escolar (ANRESC, também conhecida como Prova Brasil): avaliação censitária, também realizada a cada dois anos, dos/as alunos/as do $5^{\circ}$ e $9^{\circ}$ ano do ensino fundamental das escolas públicas municipais, estaduais e federais que possuíam, no mínimo, 20 alunos/as matriculados/as por escola; 
c) Avaliação Nacional da Alfabetização (ANA): inicialmente, se constituía em avaliação censitária dos/as alunos/as do $3^{\circ}$ ano do ensino fundamental das escolas públicas do país, realizada anualmente. A ANA foi incorporada ao SAEB pela Portaria $n^{\circ} 482$ (Brasil, 2013). Em 2018, passou a avaliar $\circ 2^{\circ}$ ano do ensino fundamental, através da Portaria $n^{\circ} 1.100$, de 26/12/2018 (Brasil, 2018). Seu objetivo era avaliar os níveis de alfabetização e letramento em Língua Portuguesa e Matemática.

Em 2019, a Portaria n 366 (Brasil, 2019), responsável pelas diretrizes para a realização do SAEB, estabeleceu duas mudanças: as siglas ANA, Aneb e Anresc deixaram de existir e todas as avaliações passaram a ser identificadas pelo nome SAEB. Em 2020, a Portaria $\mathrm{n}^{\circ}$ 458, de 05/05/2020 (Brasil, 2020c), alterou o sistema, mais uma vez, ao tornar o seu caráter censitário, em todas as etapas da Educação Básica, tendo, como público alvo, todos os alunos de escolas públicas e privadas.

O artigo faz parte de uma série de encaminhamentos inseridos em uma pesquisa, em estágio inicial, que pretende acompanhar a entrada da educação infantil como públicoalvo do SAEB e seus possíveis impactos para o trabalho pedagógico realizado nesta faixa etária em duas redes públicas municipais do estado do Rio de Janeiro'.

\section{Revisão bibliográfica sobre a questão da avaliação na educação infantil}

No primeiro semestre de 2020, como etapa inicial de pesquisa, foi realizada uma revisão bibliográfica na plataforma Scielo e no Catálogo de Teses e Dissertações da Coordenação de Aperfeiçoamento de Pessoal de Nível Superior (CAPES) com as seguintes palavras chaves:

\section{Quadro 1}

Palavras-chave utilizadas na busca realizada na plataforma Scielo e Catálogo de Teses e Dissertações da CAPES
a) avaliação da educação infantil;
b) avaliação na educação infantil;
c) avaliação em educação infantil;
d) avaliação da aprendizagem na educação infantil;
e) Sistema Nacional de Avaliação da Educação Básica;
f) SAEB;
g) Avaliação Nacional da Educação Infantil.

Fonte: elaboração própria a partir de revisão bibliográfica.

\footnotetext{
' Ainda não houve autorização oficial para a realização da pesquisa, razão pela qual os nomes das redes não serão citados no artigo.

2 A intenção é atualizar a revisão bibliográfica durante a realização da pesquisa, uma vez que o assunto que se propõe a pesquisar é relativamente novo e supõe-se que outros/as pesquisadores/as irão produzir material sobre a temática.
}

3 - Linhas Críticas, Brasília, DF, v. 26 (2020), p. 3-19 


\section{Resultados encontrados na Plataforma Scielo}

Foram encontrados os mesmos seis artigos utilizando-se das três palavras-chave avaliação da educação infantil, avaliação na educação infantil e avaliação em educação infantil. As informações estão organizadas, por ordem cronológica de publicação, na tabela 1, a seguir:

\section{Tabela 1}

Artigos disponibilizados na Plataforma Scielo com as palavras-chave "avaliação da educação infantil", "avaliação na educação infantil" e "avaliação em educação infantil"

\begin{tabular}{|c|c|c|c|c|c|}
\hline Numeração & Título & Autor & Periódico & Área & $\begin{array}{c}\text { Ano de } \\
\text { publicação }\end{array}$ \\
\hline 1 & $\begin{array}{c}\text { O que as crianças sabem } \\
\text { ao ingressarem na pré- } \\
\text { escola na cidade do Rio } \\
\text { de Janeiro? }\end{array}$ & $\begin{array}{l}\text { Tiago Lisboa Bartholo, } \\
\text { Mariana Campelo } \\
\text { Koslinski, Marcio da } \\
\text { Costa e Thais } \\
\text { Barcellos. }\end{array}$ & $\begin{array}{c}\text { Ensaio: } \\
\text { Avaliação e } \\
\text { Políticas } \\
\text { Públicas em } \\
\text { Educação }\end{array}$ & Educação & 2020 \\
\hline 2 & $\begin{array}{l}\text { Avaliação e gestão da } \\
\text { educação infantil em } \\
\text { municípios brasileiros }\end{array}$ & $\begin{array}{c}\text { Sandra Zákia Sousa e } \\
\text { Cláudia Oliveira } \\
\text { Pimenta }\end{array}$ & $\begin{array}{l}\text { Educação \& } \\
\text { Realidade }\end{array}$ & Educação & 2018 \\
\hline 3 & $\begin{array}{l}\text { Promover a partir do } \\
\text { interior: o papel do } \\
\text { facilitador no apoio a } \\
\text { formas dialógicas e } \\
\text { reflexivas de auto- } \\
\text { avaliação } \\
\end{array}$ & Anna Bondioli & $\begin{array}{c}\text { Educação e } \\
\text { Pesquisa }\end{array}$ & Educação & 2015 \\
\hline 4 & $\begin{array}{l}\text { O uso de escalas de } \\
\text { avaliação de ambientes } \\
\text { na educação infantil }\end{array}$ & Thelma Harms & $\begin{array}{c}\text { Cadernos de } \\
\text { Pesquisa }\end{array}$ & Educação & 2013 \\
\hline 5 & $\begin{array}{c}\text { Entre as políticas de } \\
\text { qualidade e a qualidade } \\
\text { das práticas }\end{array}$ & Maria Malta Campos & $\begin{array}{c}\text { Cadernos de } \\
\text { Pesquisa }\end{array}$ & Educação & 2013 \\
\hline 6 & $\begin{array}{l}\text { Avaliação de programas, } \\
\text { indicadores e projetos em } \\
\text { educação infantil }\end{array}$ & Fúlvia Rosemberg & $\begin{array}{c}\text { Revista } \\
\text { Brasileira de } \\
\text { Educação }\end{array}$ & Educação & 2001 \\
\hline
\end{tabular}

Fonte: elaboração própria a partir de revisão bibliográfica.

Com a palavra-chave avaliação da educação infantil, foram encontrados 07 artigos 3 , organizados a partir dos mesmos critérios, na tabela 2:

\section{Tabela 2}

Artigos disponibilizados na Plataforma Scielo com as palavras-chave "avaliação da educação infantil"

\begin{tabular}{cccccc}
\hline Numeração & Título & Autor & Periódico & Área & $\begin{array}{c}\text { Ano de } \\
\text { publicação }\end{array}$ \\
\hline 1 & $\begin{array}{c}\text { Avaliação de contexto na } \\
\text { educação infantil: } \\
\text { diferenciação e conflito } \\
\text { formação docente }\end{array}$ & $\begin{array}{c}\text { Luciane Maria } \\
\text { Schlindwein e Julice } \\
\text { Dias }\end{array}$ & $\begin{array}{c}\text { Pro- } \\
\text { Posições }\end{array}$ & Educação & 2018 \\
\hline 2 & $\begin{array}{c}\text { Avaliação na e da } \\
\text { educação infantil. Avaliação } \\
\text { de contexto }\end{array}$ & $\begin{array}{c}\text { Altino José Martins Filho } \\
\text { e Joselma Salazar de } \\
\text { Castro }\end{array}$ & $\begin{array}{c}\text { Pro- } \\
\text { Posições }\end{array}$ & Educação & 2018 \\
\hline
\end{tabular}

3 Um dos artigos não consta na tabela e será apresentado oportunamente no texto. 


\begin{tabular}{|c|c|c|c|c|c|}
\hline 3 & $\begin{array}{c}\text { Avaliação do Ages and } \\
\text { Stages Questionnaire-Brasil } \\
\text { por profissionais de } \\
\text { Educação Infantil }\end{array}$ & $\begin{array}{c}\text { Ana Carolina } \\
\text { Monnerat Fioravanti- } \\
\text { Bastos, } \\
\text { Alberto Filgueiras e } \\
\text { Maria Lucia Seidl } \\
\text { de Moura }\end{array}$ & $\begin{array}{l}\text { Estudos } \\
\text { de } \\
\text { Psicologia }\end{array}$ & Psicologia & 2016 \\
\hline 4 & $\begin{array}{l}\text { Políticas de educação } \\
\text { infantil e avaliação }\end{array}$ & Fúlvia Rosemberg & $\begin{array}{l}\text { Cadernos } \\
\text { de } \\
\text { Pesquisa }\end{array}$ & Educação & 2013 \\
\hline 5 & $\begin{array}{l}\text { Qualidade na educação } \\
\text { infantil: revisão de um estudo } \\
\text { Brasileiro e recomendações }\end{array}$ & Sharon Lynn Kagan & $\begin{array}{l}\text { Cadernos } \\
\text { de } \\
\text { Pesquisa }\end{array}$ & Educação & 2011 \\
\hline 6 & $\begin{array}{c}\text { Um estudo sobre creches } \\
\text { como ambiente de } \\
\text { desenvolvimento }\end{array}$ & $\begin{array}{c}\text { Ana Beatriz Rocha Lima } \\
\text { e Eliana Bhering }\end{array}$ & $\begin{array}{l}\text { Cadernos } \\
\text { de } \\
\text { Pesquisa }\end{array}$ & Educação & 2006 \\
\hline
\end{tabular}

Fonte: elaboração própria a partir de revisão bibliográfica.

Com a palavra-chave avaliação na educação infantil, foram encontrados 07 artigos, organizados a partir dos mesmos critérios, na tabela 3:

\section{Tabela 3}

Artigos disponibilizados na Plataforma Scielo com as palavras-chave "avaliação na educação infantil"

\begin{tabular}{|c|c|c|c|c|c|}
\hline Numeração & Título & Autor & Periódico & Área & $\begin{array}{c}\text { Ano de } \\
\text { publicação }\end{array}$ \\
\hline 1 & $\begin{array}{l}\text { La evaluación de la } \\
\text { calidad el juego em la } \\
\text { educación infantil }\end{array}$ & $\begin{array}{c}\text { Ângela Scabin Coutinho, } \\
\text { Catarina Moro e Daniele } \\
\text { Marques Vieira }\end{array}$ & $\begin{array}{l}\text { Caderno de } \\
\text { Pesquisa }\end{array}$ & Educação & 2019 \\
\hline 2 & $\begin{array}{l}\text { Avaliação institucional } \\
\text { e formação docente } \\
\text { como práticas } \\
\text { dialógicas na } \\
\text { educação infantil }\end{array}$ & $\begin{array}{l}\text { Maria Nilceia de Andrade } \\
\text { Vieira e Valdete Côco }\end{array}$ & $\begin{array}{l}\text { Educar em } \\
\text { Revista }\end{array}$ & Educação & 2019 \\
\hline 3 & $\begin{array}{l}\text { Avaliação do Ages } \\
\text { and Stages } \\
\text { Questionnaire-Brasil por } \\
\text { profissionais de } \\
\text { educação infantil } \\
\end{array}$ & $\begin{array}{c}\text { Ana Carolina Monnerat } \\
\text { Fioravanti-Bastos, Alberto } \\
\text { Filgueiras e Maria Lucia } \\
\text { Seidl de Moura }\end{array}$ & $\begin{array}{l}\text { Estudos de } \\
\text { Psicologia }\end{array}$ & Psicologia & 2016 \\
\hline 4 & $\begin{array}{l}\text { Políticas de educação } \\
\text { infantil e avaliação }\end{array}$ & Fúlvia Rosemberg & $\begin{array}{l}\text { Cadernos } \\
\text { de Pesquisa }\end{array}$ & Educação & 2013 \\
\hline 5 & $\begin{array}{l}\text { Autoavaliação e } \\
\text { gestão democrática } \\
\text { na instituição escolar }\end{array}$ & Itamar Mendes da Silva & $\begin{array}{c}\text { Ensaio: } \\
\text { Avaliação e } \\
\text { Políticas } \\
\text { Públicas em } \\
\text { Educação }\end{array}$ & Educação & 2010 \\
\hline 6 & $\begin{array}{l}\text { Um estudo sobre } \\
\text { creches como } \\
\text { ambiente de } \\
\text { desenvolvimento }\end{array}$ & $\begin{array}{c}\text { Ana Beatriz Rocha Lima e } \\
\text { Eliana Bhering }\end{array}$ & $\begin{array}{l}\text { Caderno de } \\
\text { Pesquisa }\end{array}$ & Educação & 2006 \\
\hline 7 & $\begin{array}{c}\text { Avaliação de } \\
\text { ambientes } \\
\text { educacionais infantis }\end{array}$ & $\begin{array}{l}\text { Mariana Almeida de } \\
\text { Oliveira; Rosângela de } \\
\text { Assis Furtado; Tatiana } \\
\text { Noronha de Souza; Mara } \\
\text { Ignez Campos-de- } \\
\text { Carvalho }\end{array}$ & Paidéia & Psicologia & 2003 \\
\hline
\end{tabular}

Fonte: elaboração própria a partir de revisão bibliográfica. 
Sobre a palavra-chave avaliação em educação infantil, foram encontrados 06 artigos, organizados por ordem cronológica de publicação na tabela 4:

\section{Tabela 4}

Artigos disponibilizados na Plataforma Scielo com a palavra- chave "avaliação em educação infantil"

\begin{tabular}{|c|c|c|c|c|c|}
\hline Numeração & Título & Autor & Periódico & Área & $\begin{array}{c}\text { Ano de } \\
\text { publicação }\end{array}$ \\
\hline 1 & $\begin{array}{l}\text { Avaliação de contexto } \\
\text { na educação infantil: } \\
\text { diferenciação e } \\
\text { conflito na formação } \\
\text { docente }\end{array}$ & $\begin{array}{c}\text { Luciene Maria Schlindwein e } \\
\text { Julice Dias }\end{array}$ & $\begin{array}{l}\text { Pro- } \\
\text { Posições }\end{array}$ & Educação & 2018 \\
\hline 2 & $\begin{array}{c}\text { Avaliação na e da } \\
\text { educação infantil. } \\
\text { Avaliação de contexto }\end{array}$ & $\begin{array}{l}\text { Altino José Martins Filho e } \\
\text { Joselma Salazar de Castro }\end{array}$ & $\begin{array}{l}\text { Pro- } \\
\text { Posições }\end{array}$ & Educação & 2018 \\
\hline 3 & $\begin{array}{l}\text { Políticas de educação } \\
\text { infantil e avaliação }\end{array}$ & Fúlvia Rosemberg & $\begin{array}{l}\text { Cadernos } \\
\text { de } \\
\text { Pesquisa }\end{array}$ & Educação & 2013 \\
\hline 4 & $\begin{array}{c}\text { A qualidade da } \\
\text { educação infantil: um } \\
\text { estudo em seis capitais } \\
\text { brasileiras }\end{array}$ & $\begin{array}{c}\text { Maria Malta Campos, Yara } \\
\text { Lúcia Esposito, Eliana } \\
\text { Bhering, Nelson Gimenes e } \\
\text { Beatriz Abuchaim }\end{array}$ & $\begin{array}{l}\text { Cadernos } \\
\text { de } \\
\text { Pesquisa }\end{array}$ & Educação & 2011 \\
\hline 5 & $\begin{array}{l}\text { A contribuição da } \\
\text { educação infantil de } \\
\text { qualidade e seus } \\
\text { impactos no início do } \\
\text { ensino fundamental }\end{array}$ & $\begin{array}{l}\text { Maria Malta Campos; Eliana } \\
\text { Bahia Bhering; Yara Esposito; } \\
\text { Nelson Gimenes; Beatriz } \\
\text { Abuchaim; Raquel Valle e } \\
\text { Sandra Unbehaum }\end{array}$ & $\begin{array}{l}\text { Educação } \\
\text { e Pesquisa }\end{array}$ & Educação & 2011 \\
\hline 6 & $\begin{array}{c}\text { Avaliação de } \\
\text { ambientes } \\
\text { educacionais infantis }\end{array}$ & $\begin{array}{l}\text { Mariana Almeida de } \\
\text { Oliveira; Rosângela de Assis } \\
\text { Furtado; Tatiana Noronha } \\
\text { de Souza; Mara Ignez } \\
\text { Campos-de-Carvalho }\end{array}$ & Paidéia & Psicologia & 2003 \\
\hline
\end{tabular}

Fonte: elaboração própria a partir de revisão bibliográfica.

Não foram encontrados registros que dissessem diretamente respeito ao estudo por meio das palavras-chave avaliação da aprendizagem na educação infantil, Sistema Nacional de Avaliação da Educação Básica, SAEB, Avaliação Nacional da Educação Infantil e ANEI.

Podemos observar que é possível encontrar o mesmo artigo nas buscas com diferentes palavras-chave, conforme organizado na tabela 1, assim como o nome de algumas pesquisadoras aparece mais de uma vez com artigos diferentes sobre a temática. Em relação ao material encontrado, para fins de organização, encontramos as seguintes categorias, descritas no quadro a seguir: 


\section{Quadro 2}

Categorias encontradas nos artigos disponíveis na Plataforma Scielo
a) avaliação de contexto;
b) avaliação de desenvolvimento infantil;
c) políticas públicas;
d) políticas e práticas escolares;
e) autoavaliação;
f) avaliação e qualidade da educação infantil;
g) avaliação e gestão.

Fonte: elaboração própria a partir de revisão bibliográfica.

\section{Resultados encontrados no Catálogo de Teses e Dissertações da CAPES}

Foram encontrados muitos registros com as palavras chave avaliação da educação infantil (1 189.596 registros), avaliação na educação infantil (1.045.308 registros), avaliação em educação infantil (1.144.595 registros) e avaliação da aprendizagem na educação infantil (1.200.806 registros). Por conta desse contexto e da dificuldade encontrada nos mecanismos de refinamento de busca, foi necessário restringi-la até o $500^{\circ}$ trabalho de cada palavra chave.

Foram encontradas as seguintes temáticas em relação às dissertações de mestrado:

\section{Quadro 3}

Categorias encontradas nas dissertações disponibilizadas pelo portal da CAPES

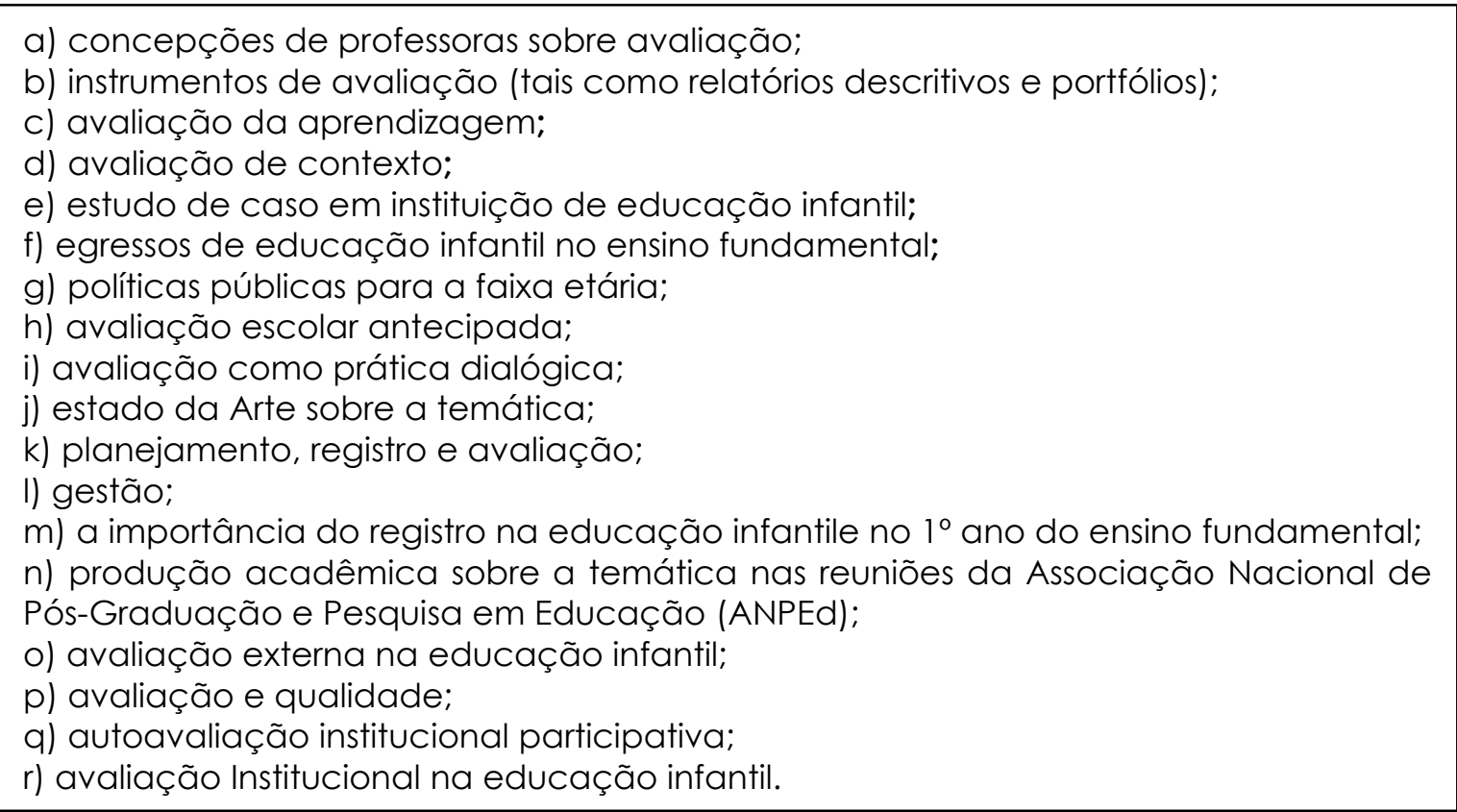

Fonte: elaboração própria a partir de revisão bibliográfica.

Em relação às teses, as seguintes temáticas foram encontradas: 


\section{Quadro 4}

Categorias encontradas nas teses disponibilizadas pelo portal da CAPES

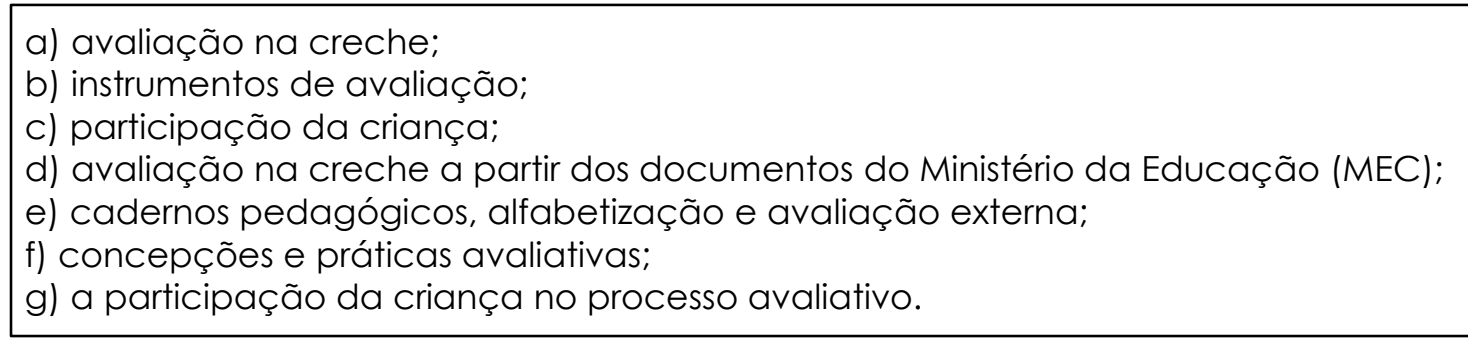

Fonte: elaboração própria a partir de revisão bibliográfica.

Sobre as palavras-chave Sistema Nacional de Avaliação da Educação Básica, SAEB, Avaliação Nacional da Educação Infantil e ANEl, não foram encontrados registros que dissessem respeito ao estudo.

Entre os artigos encontrados na busca à Plataforma Scielo, um artigo em especial está diretamente ligado à pesquisa - "Avaliação da educação infantil: questões controversas e suas implicações educacionais e sociais" (Sousa, 2018). O texto em questão "apresenta e discute proposições e iniciativas de avaliação na educação infantil que se fazem presentes no debate nacional, difundidas por gestores públicos, trabalhadores, estudiosos e pesquisadores da área." (Sousa, 2018, p. 65). A pesquisadora argumenta que os impasses presentes no cenário nacional remetem, sobretudo, à dimensão política da avaliação, uma vez que a avaliação carrega o potencial de induzir uma determinada concepção de qualidade para aqueles/as que estão envolvido/as no processo avaliativo.

Ainda para a autora, a noção de qualidade adotada acaba por condicionar o delineamento assumido para a avaliação, como as informações são produzidas e interpretadas e as escolhas que acabam se originando desse processo.

\section{Tensões entre a visibilidade da educação infantil na educação básica e a questão das avaliações externas em larga escala}

Para Sousa (2018), iniciativas para avaliar a educação infantil no contexto brasileiro são relativamente recentes. Desenvolveu-se um percurso de construção de sua inclusão nas formulações da Política Nacional de Avaliação da Educação Básica, liderado pelo MEC, que contou com a participação de representantes governamentais e não governamentais, tendo esse processo culminado com a divulgação do documento "Educação infantil: subsídios para a construção de uma sistemática de avaliação (Brasil, 2012). Com o objetivo de dar continuidade à proposta contida no documento, estabeleceu-se um acordo entre o MEC, a Secretaria de Educação Básica e a Diretoria de Avaliação da Educação Básica (DAEB) do Inep, com o objetivo de "formular uma proposta de avaliação da educação infantil" (Sousa, 2018, p. 74). 
A inclusão dessa etapa, no sistema nacional de avaliação, se materializou em 2016, com a criação do Sistema Nacional de Avaliação da Educação Básica (SINAEB), com a Portaria n 369 (Brasil, 2016a). O objetivo do SINAEB era substituir o SAEB, a fim de "assegurar o processo nacional de avaliação da educação básica em todas as etapas e modalidades, considerando suas múltiplas dimensões" (Brasil, 2016a, p. 1). O novo sistema incluiria a ANEl - Avaliação Nacional da Educação Infantil - etapa da educação básica não contemplada no sistema anterior, de ciclo bianual, com a primeira avaliação a ser realizada em 2017, com o objetivo de:

[...] realizar diagnósticos sobre as condições de oferta da educação infantil pelos sistemas de ensino público e privado no Brasil, aferindo a infraestrutura física, o quadro de pessoal, as condições de gestão, os recursos pedagógicos, a situação de acessibilidade, entre outros indicadores contextuais relevantes, além de fornecer subsídios aos sistemas de ensino para a construção de políticas públicas que possibilitem melhoria na qualidade da educação infantil. (Brasil, 2016a, p. 4).

O SINAEB, porém, não chegou a se materializar, sendo revogado pela Portaria $n^{\circ} 981$ de 26/08/2016 (Brasil, 2016b), alegando que as revisões da Base Nacional Comum Curricular (BNCC) ainda estavam em curso e que o próprio sistema a ser implementado precisava se pautar nas recomendações e orientações surgidas nesse processo. Sousa (2018) critica a justificativa de não implementação do SINAEB por conta da BNCC, uma vez que, para a pesquisadora, "ancorar a avaliação da educação infantil na Base Nacional Comum Curricular [...] indica a opção por focalizar a avaliação nas prescrições relativas ao desempenho esperado das crianças de zero a 5 anos e 11 meses de idade." (Sousa, 2018, p. 76). Para a autora, "as recentes iniciativas do governo federal permitem supor uma tendência de focalizar a avaliação no desempenho das crianças." (Sousa, 2018, p. 76).

Consideramos a preocupação de Sousa (2018) pertinente. Em 2010, na Rede Pública Municipal do Rio de Janeiro, na primeira gestão de Eduardo Paes, tendo Claudia Costin como Secretaria Municipal de Educação, os questionários ASQ-3 - Ages and Stages Questionnaires (Squires et al., 2009) foram aplicados nas creches, por amostragem. Os questionários são formados por um conjunto de 20 que cobrem intervalo etário de 1 mês a 5 anos e meio, pretendendo avaliar o desenvolvimento infantil a partir de cinco dimensões: a) comunicação; b) motora ampla; c) motora fina; d) resolução de problemas; e) pessoal/social. Segundo Neves (2012), estes questionários têm o objetivo de detectar atrasos no desenvolvimento infantil, a partir de um padrão normativo de excelência de desenvolvimento referendado na classe média branca estadunidense.

Nos anos seguintes (2011 e 2012), os questionários foram aplicados em toda a educação infantil da rede, com a intenção de estender o uso dos questionários para outras redes públicas do país ${ }^{4}$. Alguns segmentos que representam a discussão sobre a Educação Infantil, porém, posicionaram-se publicamente contra esse cenário ${ }^{5}$, apresentando

\footnotetext{
4 Disponível em: http: //www.sae.gov.br/site/?p=9623

5 Entre eles, a ANPEd, através do Grupo de Trabalho (GT - 7) - Educação da Criança de 0 a 6 anos.
}

9 - Linhas Críticas, Brasília, DF, v. 26 (2020), p. 9-19 
moção de repúdio ao MEC, ao Conselho Nacional de Educação (CNE) e a diversos órgãos competentes (Louzada, 2017).

Além de termos vivenciado essa experiência na rede pública municipal do Rio de Janeiro, ter uma parte correspondente à educação infantil na Base Nacional Comum Curricular BNCC (Brasil, 2017a) também pode apresentar um reforço à possibilidade de se promover avaliação externa em larga escala nessa etapa, embora o próprio documento defenda o acompanhamento, a observação e o registro como encaminhamentos avaliativos para a faixa etária. Em vídeo divulgado pela página da internet do Movimento Pela Base Nacional Comumb, a professora Magda Soares ${ }^{7}$ defende a necessidade de definir as metas para as avaliações externas em larga escala produzidas pelo Inep por inúmeras secretarias municipais e estaduais espalhadas pelo país. Nas palavras de Soares: "Avaliação é o quê? Avaliar metas que teriam sido definidas previamente. Mas, no Brasil, nós fizemos a coisa na ordem inversa: têm sido avaliadas as escolas e os professores sem que as metas tenham sido definidas".

Sobre o perigo eminente de se pensar iniciativas para avaliar o desenvolvimento infantil na perspectiva de se detectar atrasos, em 01/06/2020 foi publicada, na página da internet da ANPEd, um manifesto, escrito pelo Grupo de Trabalho 7 - Educação de Crianças de 0 a 6 anos - sobre "quaisquer iniciativas de avaliação em larga escala das crianças matriculadas na educação infantil, por meio de instrumentos que visem aferir domínios de competências e habilidades", alertando para os riscos da Portaria n 458 (Brasil, 2020c), que estabelece normas relativas ao SAEB sem, no entanto, explicitar como essa avaliação deve ocorrer na educação infantil, podendo resultar em proposições que desconsiderem as concepções de educação infantil e de avaliação presentes nos documentos que normatizam o trabalho pedagógico realizado com a etapa em cenário nacional.

Louzada (2017) argumenta que, inserido no contexto descrito até aqui, há interesse no trabalho pedagógico realizado nessa faixa etária, com o objetivo de melhorar o desempenho escolar futuro das crianças, uma vez que estudos sinalizam que há melhor desempenho de crianças pré-escolares se comparado com as demais (Campos et al., 2011 ). Intenciona-se antecipar a questão da alfabetização para a educação infantil, o que justificaria, por exemplo, a utilização de cartilhas e materiais pedagógicos na préescola (Louzada, 2017; Castelli et al., 2015). Iniciativas recentes confirmam essa hipótese: a) em 2017, ações de formação continuada para professores/as e equipe gestora de instituições inseridas no Pacto Nacional pela Alfabetização na Idade Certa (PNAIC) passaram a contemplar a pré-escola (Brasil, 2017b); b) em 2018, a Avaliação Nacional da Alfabetização (ANA) passou a ser aplicada no segundo ano do ensino fundamental, em vez do terceiro (Brasil, 2018); c) em 2019, a educação infantil alterou o SAEB (Brasil, 2019);

\footnotetext{
6 Disponível em: http://movimentopelabase.org.br/o-movimento

7 Esta fala pode ser encontrada no vídeo "Base Curricular de Lagoa Santa (MG) - Parte 4: Avaliação", que se refere à experiência de construção de um currículo para o ensino médio desta cidade.
} 
d) em 2020, a El foi inserida no edital do Programa Nacional do Livro e do Material Didático - PNLD $^{8}$.

Em nossos estudos, percebemos que fica difícil separar a questão da alfabetização do debate sobre aplicar avaliações externas em larga escala na educação infantil. Precisase estudar seriamente esse assunto e os seus efeitos nos cotidianos que atuam com essa faixa etária. A questão da alfabetização tem sido um grande desafio que se coloca para os/as educadores e pesquisadores/as de educação. Embora o acesso à escola tenha melhorado significativamente, tal acesso, porém, não tem garantido efetiva aprendizagem das crianças.

\section{Avaliação, alfabetização e pré-escola: um tema polêmico}

É indiscutível e legítima a preocupação com a questão da alfabetização no Brasil. Porém, temos diante de nós uma disputa de sentidos no que se refere à questão, uma vez que não é objetivo do trabalho pedagógico realizado na educação infantil antecipar os conteúdos que serão trabalhados no ensino fundamental (Brasil, 2010).

Para Sampaio (1993), o trabalho pedagógico realizado na pré-escola precisa oferecer às crianças o contato com a leitura e a escrita. No entanto, a autora adverte que esse contato precisa estar inserido em um contexto de aprendizagem em que a leitura e a escrita sejam utilizadas na plenitude de suas funções sociais.

Kramer e Abramovay (1985) defendem que a linguagem escrita se configure como uma das formas de representação e expressão no trabalho pedagógico realizado com a préescola, tendo como base o mesmo pressuposto defendido por Sampaio (1993): que a aprendizagem da leitura e da escrita tem, fundamentalmente, uma função social. As autoras também argumentam que as crianças das classes populares, muitas vezes, não têm, em seu cotidiano familiar, o mesmo convívio com o código escrito que ocorre nas classes médias; o que aumenta, e muito, a responsabilidade sobre a qualidade das experiências que thes são oferecidas nas escolas públicas.

Garantir às crianças das classes populares a apropriação de novas linguagens, inclusive a linguagem escrita, que Ihes possibilitem expressar suas formas de ser e estar no mundo, é um compromisso político. Nas palavras de Garcia,

[...] a função da educação infantil não é apenas de dar continuidade à aprendizagem da linguagem escrita, uma entre tantas linguagens, mas contribuir para que as crianças vivenciem as diferentes linguagens utilizadas na sociedade, aprendendo a ler estas linguagens e usá-las para se expressar - a linguagem corporal, a linguagem musical, a linguagem plástica, a linguagem televisiva, a linguagem

\footnotetext{
8 Disponível em: https://www.fnde.gov.br/programas/programas-do-livro/consultas/editais-programaslivro/item/11555-edital-pnld-2020
}

11 - Linhas Críticas, Brasília, DF, v. 26 (2020), p. 11-19 
Embora seja indiscutível a importância do trabalho pedagógico realizado na educação infantil para os processos formativos infantis, torna-se necessário alertar que a concepção de alfabetizar na pré-escola, que tem como ponto de partida a preparação das crianças para o ensino fundamental, empobrece as práticas pedagógicas e as relações vivenciadas nas instituições escolares. Em primeiro lugar, porque esse pressuposto tem como ponto de partida uma concepção universal de infância que enxerga crianças com o mesmo desenvolvimento e a mesma aprendizagem. Crianças entendidas a partir de uma infância (no singular) que não aprendem por conta de justificativas individuais (isentando a qualidade da intervenção oferecida através do trabalho pedagógico realizado com elas). Em segundo lugar, um trabalho voltado para a alfabetização acaba por valorizar a linguagem escrita, o que pode acarretar um trabalho pedagógico restrito em relação às diferentes linguagens - inclusive a brincadeira, linguagem extremamente importante para potencializar o desenvolvimento infantil.

Aumentando a complexidade do debate sobre o uso da avaliação externa em larga escala nessa faixa etária, torna-se necessário sinalizar que não há consenso entre os pesquisadores da área de avaliação sobre o seu uso nas demais modalidades de ensino, tendo sido o assunto, inclusive, fruto de intenso debate (Baver et al., 2015). Como discutido em seção anterior do texto, quando se pensou nessa possibilidade para a educação infantil, a intenção era avaliar as condições de oferta e de infraestrutura, não avaliar o desenvolvimento infantil.

Uma das críticas que surge a partir das avaliações externas em larga escala é que a "qualidade" do ensino tem sido usada como justificativa para ações que incentivam a terceirização da administração do sistema público, as parcerias público-privadas, os sistemas de apostilamento, entre outras (Louzada, 2017; Freitas, 2012), assim como produzem elementos importantes para a efetivação da regulação do trabalho docente (Louzada \& Marques, 2015).

O cenário descrito até aqui se configurava, porém, antes da Covid-19. Diante das diferentes concepções e disputas sobre a avaliação na educação infantil, quais são os possíveis encaminhamentos a partir desse novo contexto?

\section{E como fica a educação infantil no cenário provocado pela Covid-19?}

De acordo com o site do Ministério da Saúde, a Covid-19 é uma doença "causada pelo Coronavírus SARS-CoV-2, que apresenta um quadro clínico que varia de infecções

\footnotetext{
9 Partimos do princípio de que existem afirmações plurais de infâncias e múltiplas possibilidades de aprendizagens infantis.
} 
assintomáticas a quadros respiratórios graves 10". Os sintomas da doença podem variar de um simples resfriado até uma pneumonia severa. A transmissão pode ocorrer por meio de: tosse, espirro, catarro, gotículas de saliva, aperto de mão e objetos ou superfícies contaminadas (como celulares, maçanetas e etc.).

No dia 11 de março de 2020, a Organização Mundial de Saúde declarou pandemiall de Coronavírus. Diante de um cenário tão inusitado - pensamos que não seria exagero afirmar que nenhum de nós poderia imaginar algo parecido, talvez apenas os roteiristas da Indústria Cinematográfica de Hollywood - muitos desafios foram apresentados (e ainda se apresentam) à humanidade. No caso específico da área de educação, o principal desafio tem sido a impossibilidade de se manter aulas presenciais, levando em conta as formas de contágio da nova doença e a ausência de vacina ou medicamento efetivo para combatê-la. Tal cenário provocou a busca de alternativas para tamanho impasse, sendo uma dessas possibilidades o uso de aulas remotas para a educação básica e o ensino superior, em instituições públicas e privadas. A iniciativa, porém, tem sido alvo de acalorado debate, estando longe de alcançar consenso entre pais e responsáveis, crianças, estudantes, profissionais e pesquisadores da área.

Entendemos que enormes são os desafios que se colocam diante das instituições escolares no cenário da Covid-19, ainda mais levando-se em conta: a) as informações oscilantes sobre a doença, uma vez que até o final de 2019 era totalmente desconhecida; b) a não existência de experiências anteriores nesse quesito, considerando o seu ineditismo, que poderiam ajudar a buscar alternativas e soluções para o contexto; c) o futuro de incertezas. No caso da educação infantil, acrescentam-se a essa lista as especificidades do atendimento à faixa etária.

Até o momento de sistematização deste texto, dois documentos produzidos pelo CNE oferecem indicações para a educação brasileira no cenário pandêmico: o Parecer CNE/CP n 5 (Brasil, 2020a) e o Parecer CNE/CP nº 11 (Brasil, 2020b).

O primeiro documento, aprovado parcialmente em 01/06, traz contribuições sobre a reorganização do calendário escolar e da possibilidade de cômputo de atividades não presenciais para fins de cumprimento da carga horária mínima anual, em razão da Pandemia da Covid-19. A redação do documento foi formulada, a partir de consulta pública, de edital publicado em 17 de abril de 2020 com essa finalidade. De acordo com o documento, "foram recebidas em torno de 400 contribuições provenientes de organizações representativas de órgãos públicos e privados de educação básica e

10 "Sobre a doença", Ministério da Saúde. Disponível em: https://coronavirus.saude.gov.br/sobre-adoenca\#o-que-e-covid

11 De acordo com o Dicionário Online de Português, pandemia é uma "doença infecciosa e contagiosa que se espalha muito rapidamente e acaba por atingir uma região inteira, um país, continente etc.". Disponível em: https://www.dicio.com.br/pandemia

13 - Linhas Críticas, Brasília, DF, v. 26 (2020), p. 13-19 
superior, bem como de instituições de ensino e profissionais da área de educação, além de contribuições de pais e alunos da educação básica." (Brasil, 2020a, p. 3).

O documento em questão salienta a necessidade de se "considerar as fragilidades e desigualdades estruturais da sociedade brasileira que agravam o cenário decorrente da pandemia em nosso país" ao se pensar ações e estratégias para o cenário educacional provocado pela Covid-19, assim como "as diferenças existentes em relação às condições de acesso ao mundo digital por parte dos estudantes e de suas famílias." (Brasil, 2020a, p. 3), o longo período de suspensão das atividades educacionais em forma presencial e o impacto das medidas de isolamento social na aprendizagem dos/as estudantes.

Em relação à educação infantil, o documento destaca a inviabilidade de reposição de carga horária presencial no retorno às atividades escolares. Ressalta que algumas dificuldades encontradas nesse sentido se materializam na indisponibilidade de espaço físico, carência de profissionais para ampliação da jornada escolar diária e a impossibilidade de se quantificar em horas as experiências que as crianças pequenas terão em casa.

De acordo com o documento:

[...] sugere-se que as escolas possam desenvolver alguns materiais de orientação aos pais e responsáveis com atividades educativas de caráter eminentemente lúdico, recreativo, criativo e interativo, para realizarem com as crianças em casa, enquanto durar o período de emergência, garantindo, assim, atendimento essencial às crianças pequenas e evitando retrocessos cognitivos, corporais (ou físicos) e socioemocionais. Deste modo, em especial, evitaria a necessidade de reposição ou prorrogação do atendimento ao fim do período de emergência, acompanhando tão somente o mesmo fluxo das aulas da rede de ensino como um todo, quando do seu retorno. (Brasil, 2020a, p. 9).

Ainda de acordo com o documento, torna-se importante buscar uma "aproximação virtual" entre professores e familiares das crianças, com o uso de internet, celular ou mesmo atividades síncronas e assíncronas, para estreitar vínculos e viabilizar melhor orientação de pais e responsáveis na realização das atividades online com as crianças. Levando em conta que as mesmas aprendem e se desenvolvem, prioritariamente, brincando, tais atividades precisam estimular as crianças: a) de creche (0 a 3 anos): através de leitura de textos pelos pais, brincadeiras, jogos e músicas infantis; b) de pré-escola: através leitura de textos pelos pais ou responsáveis, desenho, brincadeira, jogos, músicas infantis e algumas atividades em meio digitais, além do estímulo para que elas possam estar envolvidas nas atividades rotineiras do espaço onde moram, transformando os momentos cotidianos em espaços de interação e aprendizagem.

Por fim, sobre a questão da avaliação, o documento se posiciona em consonância com as Diretrizes Curriculares Nacionais para a Educação Infantil (Brasil, 2010) e a Base Nacional Comum Curricular (Brasil, 2017a) na etapa da educação infantil, destacando que, nesse período, a avaliação deve ser "realizada para fins de acompanhamento e registro do desenvolvimento das crianças, sem o objetivo de promoção, mesmo para o acesso ao 
ensino fundamental", assegurando-lhes "o direito de progressão, sem retenção." (Brasil, 2020a, p. 10).

De acordo com o Parecer CNE/CP n¹1 (Brasil, 2020b), aprovado parcialmente em 03/08, que oferece orientações educacionais para a realização de aulas e atividades pedagógicas presenciais e não presenciais no contexto da pandemia, o retorno às atividades escolares demanda cautela e cuidados - não apenas em relação às questões sanitárias, mas também no que tange ao pedagógico. O documento salienta a especificidade do caso brasileiro no contexto pandêmico, uma vez que "[...] a pandemia surgiu em meio a uma crise de aprendizagem, que poderá ampliar ainda mais as desigualdades existentes." (Brasil, 2020b, p. 3).

Em relação ao planejamento de ações para o retorno de atividades escolares presenciais, o documento argumenta que são necessárias ações de: a) acolhimento, para estudantes, familiares e profissionais, levando em conta o período extenso de isolamento social; b) avaliação diagnóstica, a fim de estabelecer intervenções a partir do que nomeia como "níveis de aprendizagem" dos/as estudantes; c) reorganização do espaço físico e adoção de medidas de higiene para evitar a contaminação comunitária da COVID-19.

Levando em conta que esse retorno precisará ser gradual e que um grupo de pessoas não poderá retornar com as demais quando o funcionamento escolar for viabilizado (profissionais, estudantes e familiares em grupo de risco e/ou com quadro de comorbidade), o documento prevê a continuidade das atividades remotas em conjunto com as atividades presenciais. Sinaliza que, entre as maiores dificuldades para a implementação das atividades não presenciais no contexto de pandemia, estão: a) indefinição das normativas dos respectivos sistemas públicos de ensino; b) dificuldades dos/as professores/as em lidar com as tecnologias e a falta de equipamento; c) inclusão digital. $\bigcirc$ documento ainda salienta ser necessária uma atenção especial às medidas de combate à evasão, como busca ativa de alunos/as e estratégias de avaliação, flexibilização curricular e recuperação de aprendizagens.

Sobre a questão da educação infantil, o documento apresenta as seguintes justificativas para que os/as estudantes mais novos sejam contemplados/as prioritariamente: a) liberar mão de obra para setores da economia formal e informal; b) a possibilidade de menor impacto nos serviços de transporte público, uma vez que as crianças menores costumam morar perto da escola; c) turmas menores, o que facilita a organização do espaço físico da sala de aula, levando em conta a necessidade de distanciamento; d) menor autonomia para desenvolver atividades não presenciais.

Cabe ressaltar que o posicionamento do CNE sobre a educação infantil é alvo de debate entre pesquisadores/as e profissionais que trabalham com as infâncias, pois há a preocupação com as seguintes questões: a) o contato físico entre profissionais e crianças, principalmente entre bebês e crianças bem pequenas; b) a restrição para o uso de telas 
na faixa etária atendida pela El, de acordo com a Sociedade Brasileira de Pediatria ${ }^{12}$; c) o aumento da exclusão no que se refere ao atendimento às infâncias, uma vez que parcela significativa de crianças não tem acesso à rede e aos equipamentos digitais de qualidade. Em contrapartida, levando em conta que a entrada da etapa na educação básica é relativamente recente (Brasil, 1996), há a preocupação com a sua fragilidade diante do não atendimento remoto durante o período de suspensão das atividades presenciais.

\section{Considerações finais}

O cenário da educação infantil brasileira já se constituía como enorme desafio antes da pandemia. Diante do novo contexto, o desafio aumenta consideravelmente.

Existe o grande risco de se pensar a questão da pré-escolarização para a El, ou seja, referendar o trabalho pedagógico na concepção de que é etapa preparatória para o ensino fundamental. Com a interrupção das atividades escolares presenciais, há a grande possibilidade de termos grandes problemas em relação à alfabetização, uma vez que esse já era um problema anterior ao contexto de pandemia - que tende a piorar por conta da impossibilidade de se ter encontros presenciais por um longo período, o que pode reforçar a importância da educação infantil como estratégia para enfrentamento do problema. Nesse sentido, fazemos nossas as palavras de Rosemberg sobre as políticas de avaliação pensadas para a infância: "[...] ao integrar a educação infantil, a política (ou sistema) de avaliação da educação básica deve adequar-se a especificidades dessa etapa da educação, bem como das crianças às quais se destina" (Rosemberg, 2013, p. 53). Mais do que nunca se torna necessário termos a clareza de quais são os objetivos e as finalidades para o trabalho realizado com essa faixa etária. Ainda não temos dados de pesquisa disponíveis sobre o período pandêmico para afirmar que isso acontecerá, mas não consideramos exagero afirmar que essa possibilidade existe, uma vez que já se colocava como uma questão antes que a Covid-19 despontasse no cenário internacional.

Precisamos aguardar as políticas que serão pensadas para dar conta da educação brasileira a partir de 2020. De antemão, pode-se afirmar que, mais do que nunca, será necessário promover uma ampla discussão coletiva para se pensar futuros encaminhamentos para todas as modalidades e etapas de ensino. Não há outra possibilidade para dar conta do enorme desafio que a doença coloca diante de nós que não seja uma ampla frente para se pensar a educação, formada por profissionais e pesquisadores da área, funcionários, familiares e estudantes.

12 Disponível em: https://www.sbp.com.br/imprensa/detalhe/nid/sbp-atualiza-recomendacoes-sobresaude-de-criancas-e-adolescentes-na-era-digital 


\section{Referências}

Baver, A., Alavarse, O. M., \& Oliveira, R. P. de. (2015). Avaliações em larga escala: uma sistematização do debate. Educação e Pesquisa, 41 (spe), 1367-1384. https://doi.org/10.1590/S1517-9702201508144607

Brasil. (1994). Portaria n¹.795, de 27 de dezembro de 1994 (Cria o Sistema Nacional de Avaliação da Educação Básica). Ministério da Educação. Instituto Nacional de Estudos e Pesquisas Educacionais Anísio Teixeira. Diretoria de Avaliação da Educação Básica.

https://avaliacaoeducacional.files.wordpress.com/2016/05/docpreliminarinep.pdf

Brasil. (1996). Lei n. 9.394, de 20 de dezembro de 1996 (Estabelece as diretrizes e bases da educação nacional. Presidência da República). Presidência da República. Casa Civil. http://www.planalto.gov.br/ccivil 03/leis/19394.htm

Brasil. (2005). Portaria n931, de 21 de março de 2005. Ministério da Educação. http://download.inep.gov.br/educacao_basica/prova_brasil_saeb/legislacao/Portaria 931_NovoSaeb.pdf

Brasil. (2010). Diretrizes Curriculares Nacionais para a Educação Infantil. Ministério da Educação. Secretaria da Educação Básica.

http://portal.mec.gov.br/index.php?option=com_docman\&view=download \&alias=976 9-diretrizescurriculares-2012\&category slug=janeiro-2012-pdf\&ltemid=30192

Brasil. (2012). Educação infantil: subsídios para construção de uma proposta de avaliação (Documento produzido pelo Grupo de Trabalho instituído pela Portaria número 1.147/2011, do Ministério da Educação).

http://portal.mec.gov.br/index.php?option=com_docman\&view=download\&alias=119 90-educacao-infantil-sitematica-avaliacao-pdf\&category slug=novembro-2012pdf\&ltemid $=30192$

Brasil. (2013). Portaria $n^{\circ}$ 482, de 07 de junho de 2013 (Incorpora a Avaliação Nacional da Alfabetização [ANA] ao Sistema Nacional da Avaliação da Educação Básica [SAEB]). Ministério da Educação. https://www.in.gov.br/materia/lasset_publisher/KujinOTZC2Mb/content/id/30677986/do 1-2013-06-10-portaria-n-482de-7-de-junho-de-2013-30677978

Brasil. (2016a). Portaria n 369, de 05 de maio de 2016 (Institui o Sistema Nacional de Avaliação da Educação Básica - SINAEB). Ministério da Educação. https://www.in.gov.br/materia/lasset_publisher/Kujw0TZC2Mb/content/id/22793545/do 1-2016-05-06-portaria-no-369de-5-de-maio-de-2016-22793435

Brasil. (2016b). Portaria n 981, de 25 de agosto de 2016 (Revoga a Portaria MEC n 369 de 5 de maio de 2016, e dá outras providências). Ministério da Educação. http://portal.mec.gov.br/index.php?option=com_docman\&view=download \&alias=476 21-portaria-981-02set-pdf\&category_slug=agosto-2016-pdf\&ltemid=30192 
Brasil. (2017a). Base Nacional Comum Curricular. Ministério da Educação.

http://basenacionalcomum.mec.gov.br/images/BNCC_El_EF_110518_versaofinal_site.p $\underline{\mathrm{df}}$

Brasil. (2017b). Portaria MEC n 826, de 07 de julho de 2017 (Dispõe sobre o Pacto Nacional pela Alfabetização na ldade Certa - PNAIC, suas ações, diretrizes gerais e ação de formação no âmbito do Programa Novo Mais Educação - PNME). Ministério de Educação.

https://pesquisa.in.gov.br/imprensa/jsp/visualiza/index.jsp?jornal=1 \&pagina=20\&data= $10 / 07 / 2017$

Brasil. (2018). Portaria $n^{\circ}$ 1.100, de 26 de dezembro de 2018 (Estabelece as diretrizes para a realização do Sistema de Avaliação da Educação Básica (SAEB) no ano de 2019). Ministério da Educação. Instituto Nacional de Estudos e Pesquisas Educacionais Anísio Teixeira. https://www.in.gov.br/materia/-

Lasset publisher/Kujirw0TZC2Mb/content/id/57217372

Brasil. (2019). Portaria $n^{\circ} 366$, de 29 de abril de 2019 (Estabelece as diretrizes para a realização do Sistema de Avaliação da Educação Básica (SAEB) no ano de 2019). Ministério da Educação. Instituto Nacional de Estudos e Pesquisas Educacionais Anísio Teixeira. https://www.in.gov.br/web/dou/-/portaria-n\%C2\%BA-366-de-29-de-abril-de2019-86232542

Brasil. (2020a). Parecer CNE/CP N 5/2020 (Dispõe sobre a reorganização do Calendário Escolar e da possibilidade de cômputo de atividades não presenciais para fins de cumprimento de carga horária mínima anual, em razão da pandemia da COVID-19). Ministério da Educação. Conselho Nacional da Educação. http://portal.mec.gov.br/index.php? option $=$ com docman\&view=download \&alias $=145$ 11 -pcp005-20\&category slud=marco-2020-pdf\&ltemid=30192

Brasil. (2020b). Parecer CNE/CP No 11/2020 (Orientações Educacionais para a realização de aulas e atividades pedagógicas presenciais e não presenciais no contexto da pandemia). Ministério da Educação. Conselho Nacional de Educação.

http://portal.mec.gov.br/index.php? option=com docman\&view=download \&alias $=148$ 391-pcp011-20\&category slug=julho-2020-pdf\&ltemid=30192

Brasil. (2020c). Portaria $n^{\circ}$ 458, de 05 de maio de 2020 (Institui normas complementares necessárias ao cumprimento da Política Nacional de Avaliação da Educação Básica). Ministério da Educação. https://www.in.gov.br/web/dou/-/portaria-n-458-de-5-demaio-de-2020-255378342

Campos, M. M., Bhering, E. B., Esposito, Y., Gimenes, N., Abuchaim, B., Valle, R., \& Unbehaum, S. (2011). A contribuição da educação infantil de qualidade e seus impactos no início do ensino fundamental. Educação e Pesquisa, 37(1), 15-33. https://doi.org/10.1590/S1517-97022011000100002

Castelli, C. M., Cóssio, M. de F., \& Delgado, A. C. C. (2015). Ampliação da obrigatoriedade escolar: problematizações em relação à educação infantil. Linhas Críticas, 21 (45), 405-424. https://doi.org/10.26512/lc.v21i45.4570 
Freitas, L. C. de. (2012). Os reformadores empresariais da educação: da desmoralização do magistério à destruição do sistema público de educação. Educação \& Sociedade, 33(119), 379-404. https://doi.org/10.1590/S0101-73302012000200004

Garcia, R. L. (1993). Discutindo a escola pública de educação infantil - a reorientação curricular. Em R. L. Garcia. Revisitando a pré-escola. Cortez.

Kramer, S., \& Abramovay, M. (1985). Alfabetização na pré-escola: exigência ou necessidade. Cadernos de Pesquisa, (52), 103-107. http://publicacoes.fcc.org.br/ojs/index.php/cp/article/view/1367/1368

Louzada, V. (2017). A educação infantil no contexto das avaliações externas em larga escala. Appris.

Louzada, V., \& Marques, R. (2015). Políticas de Regulação para a Educação no Brasil: interfaces entre currículo, avaliação e formação docente. Revista e-Curriculum, v. 13 (04), 71 1-732. https://revistas.pucsp.br/curriculum/article/view/25244/18778

Neves, V. F. A. (2012). Avaliação na educação infantil: algumas reflexões. Anais da $35^{a}$ Reunião Científica da ANPEd. Porto de Galinhas. https://www.anped.org.br/biblioteca/item/avaliacao-na-educacao-infantil-algumasreflexoes

Rosemberg, Fúlvia. (2013). Políticas de educação infantil e avaliação. Cadernos de Pesquisa, 43(148), 44-75. https://doi.org/10.1590/S0100-15742013000100004

Sampaio, C. S. (1993). Alfabetização na pré-escola. Em Garcia, R. L. (org.). Revisitando a pré-escola. Cortez.

Sousa, S. Z. (2018). Avaliação da Educação Infantil: questões controversas e suas implicações educacionais e sociais. Revista de Educação PUC - Campinas, 23(1), 6578. https://doi.org/10.24220/2318-0870v23n1 a3958

Squires, J., Bricker, D., Twonby, E., \& Potter, L. (2009). Ages and Stages Questionnaires, third edition (ASQ-3): User's guide. Paul H. Brookes Publishing.

\section{Biografia}

\section{Virgínia Louzada}

Doutora em Educação pela Universidade Federal Fluminense (UFF). Professora Adjunta da Faculdade de Educação da Universidade do Estado do Rio de Janeiro (UERJ). Pesquisadora credenciada no Programa de Pós-Graduação em Educação (ProPEd), na linha de pesquisa "Infância, Juventude e Educação". Coordena o Grupo de Estudos e Pesquisas em Políticas, Avaliação e Infâncias (GEPPAI).

E-mail: virginialouzada.feveri@gmail.com

ORCID: http://orcid.org/0000-0002-0529-8091

Errata. Foram encontrados erros na versão publicada em 09/1 1/2020. Alterações foram feitas a pedido da autora. A versão atual foi republicada em 11/12/2020.

No último parágrafo da página 4, o número de artigos foi alterado de 06 para 07 . Foi incluída a nota de rodapé número 3. As notas de rodapé subsequentes foram renumeradas.

Nos quadros 3 e 4 houve a substituição da expressão "artigos disponíveis na Plataforma Scielo" por "dissertações disponibilizadas pelo portal da CAPES" e "teses disponibilizadas pelo portal da CAPES", respectivamente. 